Cite this as: $B M J 2021 ; 373: n 894$ http://dx.doi.org/10.1136/bmi.n894 Published: 06 April 2021

\section{Scholarly communications harmed by covid-19}

In this editorial by Raj Bhopal and Alasdair Munro (BMJ 2021;372:n742 doi:) we incorrectly accredited a set of principles on academic freedom to a leading UK university rather than the University and College Union. The online version has been corrected. 